\title{
PRE-FEED INTRAGASTRIC PH MEASUREMENTS IN HEALTHY PRETERM INPATIENTS
}

B. Schoonakker ${ }^{1}$, S.J. Sarno ${ }^{2}$, N.J. Rowbotham ${ }^{2}$, S. Ojha ${ }^{3}$, H. Budge ${ }^{3}$

${ }^{1}$ Neonatal Intensive Care Unit, Nottingham University NHS Trust, ${ }^{2}$ University of Nottingham, ${ }^{3}$ Early Life Nutrition Research Unit, Academic Child Health, University of Nottingham, Nottingham, UK

Background and aims: The normal Reflux Index (percentage time with $\mathrm{pH}<4$ ) in preterm infants has a wide range $(0.7-11.9 \%)$ reflecting the limited data for preterm infant. A recent UK National patient safety alert led to a change in practise requiring that the position of a nasogastric tube has to be confirmed by checking the acidity of gastric aspirates prior to a feed.

Methods: The $\mathrm{pH}$ of gastric contents $(\mathrm{n}=1727)$ were recorded in 38 inpatients in an NICU using $\mathrm{pH}$ indicator strips.

Results: The period over which data was collected equated to 215 patient days. Infants had a mean postmenstrual age of 32 weeks (range 27-40). The pH testing strip measurements were reproducible (coeff. var.: $3.21 \pm 1.7 \%$ (mean \pm s.e.m.)) and comparable to those obtained by standardised $\mathrm{pH}$ meter (mean difference: -0.3 to $0.3 ;{ }^{1.96} \mathrm{SD}$ : 0.48$)$ ). The median $\mathrm{pH}$ for all the observations was 3.5 (IQR 1.5). Infants who were nil by mouth had a significantly lower median gastric $\mathrm{pH}$ than those who were bolus milk fed.
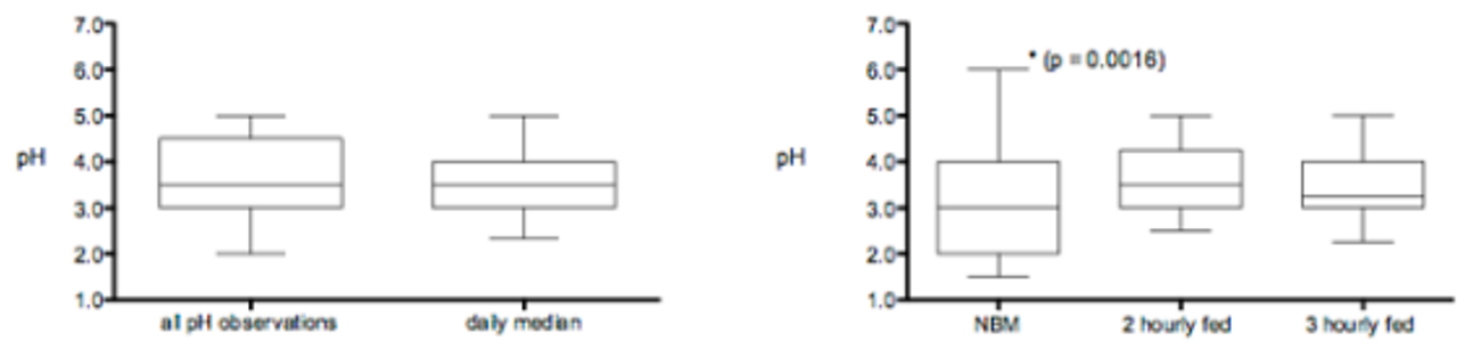

[pH data, median, 5- 95th percentile]

Conclusions: The median gastric $\mathrm{pH}$ value of 3.5 in our preterm population is lower than expected from previous published data on Reflux Index. This was not affected by the feeding interval, although gastric $\mathrm{pH}$ was lowest in infants who were nil-by-mouth. 